\title{
Interview with Dr. Steven Smith - a Scientific Advisor at GSK
}

\author{
By Rebecca Liu
}

"Steve Smith completed his PhD at McMaster University and Post-doctoral training at St. Joseph's Hospital in the Firestone Institute for Respiratory Health. Mr. Smith currently works as a Scientific Advisor in the respiratory division of GlaxoSmithKline. This experience has allowed him to work as a member of an interdisciplinary team, and participate in grant and pharmaceutical sponsored trials, which have had varying degrees of complexity and challenges."

1) What unique non-academic skills do you believe are most valuable in your current position?

The great thing about academics is that you develop a range of skills that are not all about techniques and the ability to reference a paper from memory. For example, I developed the skills to manage people while I was a graduate student. I developed the skill of communicating complex ideas in an understandable manner. And last but not least, I developed the skill to know how to challenge myself and reflect on how to improve.

2) Can you briefly describe one of the projects you are currently working on?

In the Medical Affairs department, we engage with the scientific community to better understand the needs of patients through sharing ideas with health care professionals.

3) What are some of the major benefits and drawbacks of your current position and how does it relate to your training in allergy and autoimmunity (if applicable)?

The major benefit of my position is that I am able to utilize the knowledge I gained as a graduate student in the Department of Allergy and Immunology to engage with the scientific community. As mentioned above, academics provides you with the skills you need to achieve at a high level in any career path.

4) Can you describe the landscape and scope of opportunity within your field for Master's and PhD-trained students?

My department is comprised of PhDs and MDs. There are very few MSc's in Medical Affairs.

5) Can you give any advice to graduate students looking to pursue a career within your field?

Get clinical experience. The reason I believe I was selected for the position is that I had direct clinical experience. My $\mathrm{PhD}$ was in a lab that performed clinical trials, so I was familiar with the pharma industry and how they interact with academics. Also, be open to any position available. You never know. You might like a pharma position that you weren't thinking of initially when deciding on potential career paths.

6) What are some resources (websites, readings, listings) that you can recommend for graduate students interested in this field?

Unfortunately, the pharma industry is very closed off. I am still learning of new positions, and still don't know of all of the positions available. The best thing to do is to discuss your ideal position with someone that is already in that position, and they might be best able to help you navigate the complex system. 